\title{
CICLO DE VIDA CONJUGAL: MOMENTOS DE ESTRESSE PREVISÍVEIS E IMPREVISÍVEIS AO LONGO DO CASAMENTO
}

CYCLE OF MARRIED LIFE: MOMENTS OF PREDICTABLE AND UNPREDICTABLE STRESS THROUGHOUT MARRIAGE

CICLO DE VIDA CONYUGAL: MOMENTOS DE ESTRÉS PREVISIBLES E IMPREVISIBLES EN EL MATRIMONIO

\author{
Aline Amaral Mussumeci ${ }^{*}$ \\ Edna Lúcia Tinoco Ponciano ${ }^{* *}$
}

\begin{abstract}
RESUMO
O objetivo deste artigo é analisar o estresse e as estratégias de coping durante o ciclo de vida conjugal, trazendo trechos de entrevistas de uma pesquisa qualitativa com casais heterossexuais de famílias intactas (nucleares) da classe média do Rio de Janeiro e de Curitiba. A maneira como os cônjuges administram as situações de estresse, e diversas transformações relativas ao desenvolvimento do casamento, pode trazer consequências para o casal, durante o ciclo de vida. Realizamos entrevistas semiestruturadas, seguindo um roteiro e sendo gravadas em áudio. Após a transcrição, procedemos à análise de conteúdo. Concluímos que o momento inicial do casamento é o mais estressante e os outros períodos do ciclo de vida refletem o enfrentamento construído inicialmente, sendo a base para as formas de enfrentamento posteriores, vividas ao longo da trajetória conjugal.

Palavras-chave: Ciclo de vida. Estresse. Casamento.
\end{abstract}

\begin{abstract}
The goal of this paper is to analyze the stress and coping strategies during the cycle of married life, bringing excerpts from interviews of a qualitative study of heterosexual couples of intact (nuclear) middle-class families in Rio de Janeiro and Curitiba. The way spouses deal with the situations of stress and various changes related to marriage development, may have bring consequences for the couple during the life cycle. We conducted semi-structured interviews, following a script and recorded in audio. After transcription, we carried out a content analysis. We concluded that the initial moment of marriage is the most stressful one and the other periods
\end{abstract}

\footnotetext{
Texto recebido em 5 de outubro de 2016 e aprovado para publicação em 31 de março de 2017.

"Mestra em Psicologia Social pela Universidade do Estado do Rio de Janeiro (UERJ). Endereço: Rua Brigadeiro Franco, 1909, ap. 501 - Centro, Curitiba-PR, Brasil. CEP: 80420-200. E-mail: aline.mussumeci@gmail.com.

"* Professora adjunta do Instituto de Psicologia da UERJ, Rio de Janeiro-RJ, Brasil. Endereço: Instituto de Psicologia, Universidade do Estado do Rio de Janeiro, Rua São Francisco Xavier, 524, 10 andar - Maracanã, Rio de Janeiro-RJ, Brasil. CEP: $20550-013$. E-mail: ednaponciano@uol.com.
} 
of the life cycle mirror the confrontation that was initially built, being the foundation for later coping experiences, lived throughout the marital trajectory.

Keywords: Life cycle. Stress. Marriage.

\section{RESUMEN}

El objetivo de este trabajo es analizar el estrés y las estrategias de supervivencia durante el matrimonio, con extractos de entrevistas de un estudio cualitativo con parejas heterosexuales de familias intactas (nucleares) de clase media, en Río de Janeiro y Curitiba. La forma en que los cónyuges manejan las situaciones de estrés y varios cambios relacionados con el desarrollo del matrimonio, pueden tener consecuencias para la pareja durante el ciclo de vida. Hemos llevado a cabo entrevistas semiestructuradas, siguiendo un guión, y grabando en audio. Después de la transcripción, se realizó un análisis de contenido. Llegamos a la conclusión de que el momento inicial del matrimonio es el más estresante y los otros periodos del ciclo de vida reflejan la confrontación construida inicialmente, siendo la base de las formas de hacer frente más adelante, vivida a lo largo de la trayectoria conyugal.

Palabras clave: Ciclo de vida. Estrés. Matrimonio.

\section{INTRODUÇÃO}

$\mathrm{D}$ urante o ciclo de vida, os cônjuges vivenciam situações de estresse, dificuldades, mudanças cotidianas e diversas transformações relativas ao desenvolvimento do casamento. Nesse percurso, os casais estabelecem estratégias para lidarem com as situações de estresse, além de elegerem diversas maneiras de adaptação às transformações. A forma como os cônjuges administram essas situações pode facilitar ou dificultar esse processo, trazendo consequências para o casal, durante o ciclo de vida conjugal. Em uma pesquisa exploratória, abordamos a história conjugal, investigando as estratégias de coping eleitas pelos casais durante os diferentes momentos de estresse. Tanto o indivíduo quanto o casal e a família têm um ciclo vital, com fases diferenciadas e tarefas particulares. O desenvolvimento ocorre conforme uma sequência, não linear, de eventos com alguns episódios considerados esperados e, outros, imprevisíveis. Não sendo necessariamente negativas, as mudanças imprevisíveis apresentam novos desafios e novas organizações para indivíduos, casais e famílias, que se afetam mutuamente (Carter \& McGoldrick, 2001; Baltes, 1987; 1997).

O objetivo deste artigo é analisar, ao longo do ciclo de vida conjugal, os momentos de estresse e as estratégias de coping eleitas pelos casais, trazendo 
trechos de entrevistas de uma pesquisa qualitativa com casais heterossexuais de famílias intactas (nucleares e heterossexuais) da classe média das cidades do Rio de Janeiro e Curitiba. Para tanto, realizamos entrevistas com um roteiro semiestruturado, sendo gravadas em áudio. Dessa maneira, as estratégias de coping utilizadas pelos casais, para lidar com os estresses e as dificuldades da vida podem ser narradas pelos próprios, e por nós analisadas, discutindo as repercussões para o desenvolvimento conjugal.

Estudos sobre a caracterização e a avaliação da qualidade do laço conjugal consideram a importância do momento do ciclo de vida familiar em que se encontra o casal, partindo-se da ideia de que é praticamente impossível estudar aspectos do casamento e da relação amorosa sem considerar os conceitos relativos à dinâmica familiar (Féres-Carneiro, 2003). Analisar a família, a partir das etapas do ciclo vital, auxilia-nos a analisar os processos esperados e previsíveis do desenvolvimento humano, inclusive processos críticos que acarretam transformações pessoais e do sistema relacional (Menezes \& Lopes, 2007).

Baltes (1987; 1997) distingue, no ciclo vital, a sequência de mudanças previsíveis e não previsíveis. As primeiras se referem às influências normativas, de natureza genético-biológica, graduadas por idade, ou ontogenéticas, sendo eventos que tendem a ocorrer na mesma época e com a mesma duração, para a maioria dos indivíduos. A segunda sequência de mudanças representa as influências não normativas, aquelas que não afetam todos os indivíduos de um grupo etário ao mesmo tempo, isto é, não dependem da ontogenia e do tempo histórico. Sua ocorrência é de caráter imprevisível, podendo ser de natureza biológica ou social.

Partimos da concepção de que o ciclo de vida familiar/conjugal é dividido em cinco etapas, enfatizando as nuances de cada período com a centralidade do casal e as fontes de estresse de cada momento. A primeira fase se concretiza com a formação do novo casal, em que os parceiros têm o desafio de estabelecer um compromisso permanente. Nessa fase, é necessária a criação de uma independência emocional da família de origem, para a constituição da própria família (Vásquez, Posada, \& Messager, 2015). Nesse processo de construção de regras próprias, a partir da elaboração das regras das duas famílias de origem, o casal necessita lidar e aceitar com as diferenças de crenças, de hábitos, que podem gerar conflitos. É esperado nos primeiros anos de casamento uma capacidade de adaptação maior, derivada dos contrastes entre o que se espera da relação e como se apresenta na realidade, as diferenças entre os parceiros e a construção da conjugalidade (Lima \& Alves, 2010). 
A segunda fase se estabelece com a chegada do novo membro. As responsabilidades com a criança exigem uma nova forma de compromisso, o que traz renegociação das regras do sistema, que estavam estabilizadas, podendo gerar estresse. Considerando que as tarefas são desconhecidas e numerosas, é provável que ocorram conflitos entre o casal, relacionados ao desgaste físico e emocional, pelo excesso de tarefas, às novas funções como mãe e pai e à falta de privacidade para a atividade sexual (Vásquez et al., 2015). Hernandez e Hutz (2009) apontam os seguintes fatores como responsáveis pelo aumento do conflito conjugal nessa fase do ciclo vital: a vulnerabilidade das pessoas à depressão; retorno aos papéis estereotipados de gênero; quantidade de trabalho doméstico e cuidados com a criança; o refúgio dos homens no trabalho externo; diminuição da comunicação e do sexo.

A terceira fase é a do casal com filhos pequenos. Esse período é marcado por dedicação e tempo com os filhos que estão num momento que requer muitos cuidados e atenção (Carter \& McGoldrick, 2001). Os pais precisam tolerar e controlar o comportamento dos filhos como também suportar o cansaço que a criança provoca (Vásquez et al., 2015). Se os cônjuges não administrarem bem, as vicissitudes desse período podem trazer estresse para o casal (Whiteman, McHale, \& Crouter, 2007). A conjugalidade é um suporte para a parentalidade, pois a intimidade e a comunicação entre os pais no casamento possibilita maior afeto com seus filhos (Grych, 2002).

A quarta fase é caracterizada por maior autonomia dos filhos, compreendendo a adolescência e a adultez emergente, e pela necessidade de cuidar dos pais (Carter \& McGoldrick, 2001; Ponciano, 2015; Ponciano \& Féres-Carneiro, 2014; Ponciano \& Seidl-de-Moura, 2011). A adolescência pode ser demarcada por frustrações dos pais ao perceberem que suas expectativas em relação aos filhos e filhas não foram atendidas, gerando dificuldades de aceitação das possíveis condutas disruptivas do filho ou da filha adolescente. Os filhos e filhas podem temer sair de casa, devido às consequências que podem surgir na relação conjugal dos seus pais (Vásquez et al., 2015). Por conseguinte, no momento em que o casal alcança maturidade para inovar em sua dinâmica conjugal, a independência/dependência dos filhos e a fragilidade dos avós são, ao mesmo tempo, uma oportunidade e uma fonte de estresse (Mussumeci, 2016; Mussumeci \& Ponciano, 2016).

A última fase denominada "estágio tardio da vida" se caracteriza pela necessidade de aceitação dos papéis geracionais com a finalidade de manter o funcionamento e os interesses próprios e, ou, do casal em fase do declínio fisiológico. É um momento em que o casal tem cada vez menos habilidades físicas e motoras, podendo ter altos custos financeiros com a saúde. Além disso, 
os cônjuges lidam com múltiplas perdas: juventude, vitalidade, trabalho, morte do parceiro, que podem acarretar um significativo impacto emocional (Vásquez et al., 2015).

Em geral, no processo de desenvolvimento, o estresse familiar é maior nos pontos de transição de uma fase para a outra, e os sintomas tendem a emergir quando há uma interrupção ou deslocamento no ciclo de vida familiar. Cada fase do ciclo de vida deflagra características específicas de mudanças e de estresse que influenciam o relacionamento conjugal (Carter \& McGoldrick, 2001). É relevante considerar que cada fase do ciclo de vida familiar requer um processo de adaptação da díade conjugal e que a forma como o casal vivenciará esses momentos trará repercussões para o bem-estar da conjugalidade (Bolze, Schmidt, Crepaldi, \& Vieira, 2013).

Atualmente não faz sentido buscar um simples conceito para o estresse (Faro \& Pereira, 2013; Moal, 2007), e diferentes campos de pesquisa se dedicam ao estudo das inúmeras facetas do estresse. Lazarus (1993) define estresse com base em quatro construtos:

a) a presença de uma causa externa ou interna (agente);

b) a existência de uma avaliação (por meio de um processo mental ou do sistema fisiológico);

c) processos de coping (mecanismos mentais ou corporais para manejar o estresse);

d) a ocorrência de um padrão de efeitos sobre a mente e o corpo (geralmente remetido às reações de estresse).

Há um destaque para a avaliação cognitiva, pois influencia diretamente a qualidade da resposta emocional do indivíduo e as formas pelas quais lida com a interface pessoa/ambiente, nos comportamentos de coping. Nesse sentido, o relacionamento entre a pessoa e o ambiente é bidirecional e recíproco. A avaliação cognitiva, que cada pessoa executa sobre a possibilidade de controle da situação, está atrelada a essa inter-relação. Portanto o significado de um evento, a respeito do seu caráter ameaçador, depende dos processos de avaliação cognitiva: avaliação primária, secundária e reavaliação (Folkman \& Lazarus 1980; Lazarus \& Folkman, 1984).

Com base nessa referência, definimos estresse como um processo psicológico no qual variáveis cognitivas interferem no entendimento dos eventos estressantes, 
não sendo o evento nem a resposta os determinantes da experiência de estresse (Lazarus \& Folkman, 1984). O estresse se refere a um desequilíbrio entre o que é percebido pelo indivíduo como demanda e sua capacidade de enfrentamento, isto é, a avaliação cognitiva da situação que define a experiência ou não de estresse. Desse modo, o indivíduo tem um papel ativo no processo de estresse, implementando estratégias de coping emocionais, comportamentais e cognitivas que influenciam no impacto do estressor.

Quando o casal utiliza habilidades positivas de enfrentamento, que potencializam a resolução do evento estressante, a vivência de uma experiência negativa pode se tornar positiva para a relação conjugal, uma oportunidade para cada um dos cônjuges dar suporte ao outro, reforçar sentimentos positivos e aumentar a proximidade (Bodenmann, 2005; Bodenmann, Meuwly, \& Kayser, 2011), sendo uma oportunidade para os casais reforçarem a sua relação (Story \& Bradbury, 2004).

O gerenciamento das situações estressantes dificilmente acontece de modo isolado. As relações íntimas são constituídas pela interdependência e as estratégias de coping, e as experiências de estresse são permeadas pela intersubjetividade. A dinâmica interpessoal possibilita uma maior fluidez nas respostas emocionais, com a presença de cooperação, o que permite alívio às tensões, suporte em situações estressantes e restabelecimento do equilíbrio físico e, ou, emocional (Oatley \& Jenkins, 2002). Uma forte ligação com os outros caracteriza as pessoas que são mais felizes, mais saudáveis, mais capazes de lidar com as tensóes e menos propensas a experimentar problemas psicológicos e somáticos de saúde (Baumeister \& Leary, 1995; Lakey \& Orehek, 2011; Rook et al., 2012). Os estudos sobre coping diádico têm demonstrado que essa forma de enfrentamento está vinculada a uma maior qualidade conjugal, a baixos níveis de tensão, a menos problemas psicológicos, ao maior bem-estar físico e a maior estabilidade das relações (Pires, 2011).

Assim, o ciclo vital representa os períodos evolutivos de crise, que ocorrem em todas as famílias, e os eventos imprevisíveis, que podem ser caracterizados por conflitos e ansiedade, ocasionados pelas rupturas nas regras e padróes de funcionamento, até então estabelecidos. No entanto, em todos os períodos, podem ser desenvolvidas habilidades que auxiliam na capacidade adaptativa. 


\section{METODOLOGIA}

Participaram desta pesquisa dez casais com idade entre 27 e 74 anos, estrategicamente selecionados em diferentes fases do ciclo de vida, para observar vários momentos da história conjugal. Divulgamos os critérios para que fossem indicados por pessoas conhecidas. Nesse sentido, esclarecemos que se trata de uma amostra de conveniência, em que os entrevistados preencheram os seguintes critérios: heterossexuais de famílias intactas, casados por tempo variado, de qualquer idade, com filhos ou filhas de idades e de gênero variados ou sem filhos. Os entrevistados e entrevistadas foram identificados pelas letras $\mathrm{M}$ (mulher) e $\mathrm{H}$ (homem), seguido por um número de 1 a 10, correspondendo a cada casal.

Inicialmente, foi elaborado um projeto, avaliado e aprovado pelo Comitê de Ética em 17 de julho de 2015, sob o registro de número 42129415.6.0000.5282. Utilizamos entrevista semiestruturada com perguntas norteadoras, sendo gravadas em áudio, com o intuito de analisar as estratégias de coping, as respostas ao estresse e as experiências emocionais correlatas, com o seguinte roteiro: como vocês se conheceram?; falem dos momentos importantes da vida de vocês (individuais, conjugais, positivos e negativos); como lidaram com esses momentos?; que emoções vocês vivenciaram nestes momentos? (vivência de cada um e como foi ver a experiência do outro); que influências vocês tiveram nesses momentos? Os casais assinaram termo de consentimento livre e esclarecido. As entrevistas foram transcritas e, posteriormente, os dados foram analisados de acordo com a análise de conteúdo (Bardin, 2008), utilizando-se da técnica de análise temática e categorial, que consiste em desmembrar o texto em eixos temáticos, estabelecendo núcleos de sentido e, posteriormente, identificando categorias conceituais e descritivas, possibilitando uma compreensão sobre os significados e a vivência dos cônjuges diante de situaçôes de estresse.

Primeiramente, submetemos cada entrevista a uma análise, buscando a temática de base e a lógica interna de cada entrevista. Para a escolha dos temas, considerando o objetivo da pesquisa, foi realizada uma leitura flutuante, demarcando núcleos de sentido de cada entrevista (decifração estrutural) e, posteriormente, estabelecendo relações entre elas, a partir da repetição de alguns temas significativos. Por conseguinte, desmembramos o texto em eixos temáticos, estabelecendo núcleos de sentido e suas respectivas categorias.

Os temas e as categorias foram selecionados conforme a presença no relato dos entrevistados, sendo associados à vivência de suas experiências. Neste artigo, abordamos o eixo "ciclo de vida", com categorias relativas aos momentos previsíveis e imprevisíveis, e algumas fases do ciclo de vida conjugal, apresentados no quadro 1 e, posteriormente, descritos, exemplificando com as 
falas dos entrevistados. A escolha de temas e de categorias foi demarcada por um critério, o da compreensão baseada na narrativa, estando de acordo com uma das possibilidades técnicas de análise de conteúdo, proposta por Bardin (2008).

A decisão sobre o fechamento da amostra em dez casais foi feita pela seleção de um casal para cada momento do ciclo de vida, sendo ainda confirmada pela saturação. Para tanto, utilizamos um método chamado saturação teórica, que consiste na suspensão da inclusão de novos participantes quando os dados obtidos, na avaliação do pesquisador, começam a ser repetitivos e torna-se irrelevante persistir na coleta de dados, ou seja, os dados fornecidos por novos participantes não contribuiriam significativamente para o aperfeiçoamento da reflexão teórica, sendo uma decisão fundamentada nos dados que foram coletados (Fontanella, Rica, \& Turato, 2008). Esse método está respaldado cientificamente pelo pressuposto da constituição social do sujeito que, na teoria das representações sociais, repercute no conceito de determinação social das representações individuais e, na análise do discurso, no conceito de determinação histórica e social das formações discursivas e da fala. O entendimento é o de que a representatividade da amostra não é alcançada apenas estatisticamente, no domínio matemático, mas sim cognitivamente, envolvendo a percepção do pesquisador e de seu domínio teórico (Fontanella et al., 2008). O quadro 1 apresenta a saturação teórica do eixo "ciclo de vida", listando as categorias aqui analisadas, dispostas horizontalmente, e os números das entrevistas, verticalmente. Seguindo os relatos dos entrevistados, se as categorias eram apresentadas, marcamos com um $\mathrm{X}$ na respectiva entrevista avaliada. 
Quadro 1 - Distribuição das categorias e subcategorias por saturação - Eixo "ciclo de vida"

\begin{tabular}{|c|c|c|c|c|c|c|c|c|c|c|c|c|c|}
\hline $\begin{array}{c}\text { Eixo } \\
\text { temático }\end{array}$ & Categorias & Subcategorias & Entr1 & Entr2 & Entr3 & Entr4 & Entr5 & Entr6 & Entr7 & Entr8 & Entr9 & Entr10 & Total \\
\hline \multirow{5}{*}{$\begin{array}{l}\text { Ciclo de } \\
\text { vida }\end{array}$} & $\begin{array}{c}\text { Formação do novo } \\
\text { casal }\end{array}$ & & $x$ & $x$ & $x$ & $x$ & $x$ & $x$ & $x$ & $x$ & $x$ & $x$ & 10 \\
\hline & Conjugalidade & & & $x$ & & $x$ & $x$ & $x$ & & $x$ & $x$ & $x$ & 7 \\
\hline & $\begin{array}{c}\text { Casal e } \\
\text { parentalidade }\end{array}$ & & & $x$ & $\mathrm{x}$ & $\mathrm{x}$ & $x$ & $x$ & & $x$ & $x$ & $x$ & 8 \\
\hline & $\begin{array}{l}\text { Momentos } \\
\text { imprevisíveis }\end{array}$ & & & $x$ & $x$ & $x$ & $x$ & $x$ & $x$ & $x$ & $x$ & $x$ & 9 \\
\hline & $\begin{array}{l}\text { Momentos } \\
\text { previsíveis }\end{array}$ & & $x$ & $x$ & & $x$ & $x$ & & & & $x$ & $x$ & 6 \\
\hline
\end{tabular}

Nota: Entr $=$ entrevista

Fonte: elaborado pelas autoras. 


\section{RESULTADOS}

\subsubsection{Ciclo de vida}

Aborda os fenômenos previsíveis e imprevisíveis ao longo do tempo, como um processo de expansão, contração e realinhamento do sistema de relacionamentos, para suportar a entrada, a saída e o desenvolvimento dos membros da família, assim como assimilar variados acontecimentos (Baltes, 1987; 1997; Carter \& McGoldrick, 2001).

\subsubsection{Formação do novo casal}

O início do ciclo de vida conjugal estabelece a união de duas famílias pelo casamento. Para a maioria dos casais, caracteriza-se por um tempo de adaptação, podendo gerar conflitos e dificuldades conjugais (Carter \& McGoldrick, 2001).

Bom, primeiro mês de casamento, fachada. Esse negócio de lua de mel, maravilhoso, para a gente não foi. A gente teve muita dificuldade de adaptação. Por mais que eu achava: "Ah! Eu vou casar, eu sei que H1 é assim, eu sei que [. . . ]" Lógico, a gente tem um entrosamento, como todo mundo fala, todo mundo percebe, lógico a gente também sabe. Mas não foi, a gente discutia por coisas assim, sabe? (M1)

Você vem com costumes e hábitos diferentes na sua casa. Sei lá, vou dar exemplo qualquer: ah, eu tenho o hábito de chegar em casa e tirar o sapato, deixar ali. Eu tenho hábito de chegar, tirar minha blusa e colocar ali. "Pô, eu acho horrível colocar sua blusa ali, aquilo me incomoda", "E eu acho o seu sapato horrível ali". Aí começa, né? Sim, é por isso, coisas pequenas, coisas bobas. Ah, porque, na minha casa, era assim, na minha casa era assado. Pô, eu não gosto disso! "Eu também não gosto daquilo" (M5).

Os membros do casal 1 e 5, trouxeram as dificuldades de adaptação que vivenciaram no começo do casamento, na constituição da conjugalidade. M1 retrata que, mesmo sabendo dos defeitos do marido, tiveram muitos conflitos e acrescenta: "Primeiro mês de casamento. [. . .] Esse negócio de lua de mel, maravilhoso. [. . .] Fachada". M5 também relata que tiveram conflitos nessa fase do ciclo de vida, por conta dos diferentes hábitos de cada um, anteriores ao casamento. 


\subsubsection{Conjugalidade}

Processo de construção de uma realidade comum, de uma identidade compartilhada. Cada parceiro, ao se engajar na relação a dois, experimenta uma reconstrução de sua realidade individual, criando referências comuns e uma identidade conjugal (Féres-Carneiro, 1998).

Até você achar o jeito do casal, o jeito de nós dois, que não éo meu jeito nem o da casa dele. $E$ o jeito da nossa casa. Leva um tempo, e eu acho que o tempo para a gente foi supercurto (M5).

O lance é respeitar a individualidade de cada um $(\mathrm{H} 5)$.

Às vezes, eu acho que gasto em coisas que não deveria gastar, e ele também gasta em coisas que não deveria gastar. E a gente nunca conseguiu somar isso. [. . .] Cada um decidir da sua maneira como gastar o dinheiro, fazendo coisas para os dois, mas separadamente, não planejando juntos. [. . .] Ele sempre quis, desde o início do casamento. Isso é uma dificuldade minha, não é dele, é minha (M2).

Como eu vejo essa dificuldade? Eu respeito o espaço dela. Se ela optou por gastar o dinheiro dela independente de planejamento, eu respeito o espaço dela. O dinheiro é dela, ela faz o que ela quiser. [. . . ] Não há concordância nessa área entre nós dois. Nesse ponto, há divisão e não concordância $(\mathrm{H} 2)$.

A maior parte dos entrevistados lembrou-se de situações no casamento que remetiam às diferenças individuais e à construção da identidade conjugal, conforme as falas acima. O casal 5 aponta que o processo da construção da conjugalidade foi difícil para ambos, mas destacaram que esse período foi curto, comparado a outros casais. O último relato acima apresenta o diálogo entre $\mathrm{M} 2$ e H2, seus posicionamentos diferentes quanto aos investimentos e gastos do salário de cada um, demonstrando um impasse entre a individualidade e a conjugalidade.

Mas uma coisa que é boa. É que ele me deixa viver livre; e eu também, ele tem o mundo dele à parte. Ele tem as coisas dele, as coisas que ele gosta, as leituras, o que ele quiser fazer de curso ele faz. Se quiser fazer outra faculdade, ele faz, e eu respeito o espaço dele. E ele faz a mesma coisa comigo. Se eu quiser viajar, fazer alguma coisa sozinha, ele deixa, porque a gente confia plenamente um no outro (M2).

M2 ainda valoriza o fato de ambos respeitarem a individualidade e as diferenças, que cada um tem liberdade para fazer a atividade que gosta e respeita o espaço do outro. Destaca ainda que isso contribui para o bem-estar do casal e do tempo que estão fazendo atividades em conjunto. 


\subsubsection{Casal e parentalidade}

Relaciona a conjugalidade ao funcionamento de ambos como pais. Requer a união do casal, para aceitação de novos membros no sistema familiar, por meio do ajuste do sistema conjugal, para criação de espaço para os filhos e a negociação das regras de funcionamento (Carter \& McGoldrick, 2001).

Fui trabalhar em outro lugar. Isso tudo também gerou um certo cansaço, porque eu ficava longe da família. Saía de casa, a filha estava dormindo (M3).

O nosso relacionamento deixa de ser o foco para ter o foco no filho. Então o nosso relacionamento fica um pouco apagado. [. . .] Não tem tempo pra dormir, você não tem tempo para fazer suas coisas básicas, que dirá cuidar, olhar (M5).

Os casais destacaram questōes relevantes da parentalidade, entre elas as dificuldades de coadunar a vida profissional e o cuidado com os filhos, a educação e a falta de tempo, a partir do nascimento.

Mesmo assim, não atrapalhou em nada. Saíamos para comprar roupa, para comprar coisas e para namorar também. A gente viveu como se eu não estivesse grávida, eu estando grávida. Foi muito bom (M2).

Quando a gente era só sem os filhos, né amor? Era bem diferente. Vida de casado sem os filhos é bem diferente, né (M9).

Quando é pequenininho, é diferente, você cuida você trata e tal, tem certo controle, sabe? Um domínio da situação. Mas depois que aquilo toma uma proporção diferente, tudo muda, e muda, e muda mesmo. [...] É difícil! Educar é uma arte (M4).

Porque, assim, a gente casado, só nós dois, por mais que a gente tenha experiência, os filhos, $e ́$ não tem uma palavra certa. As maiores emoçôes do casamento foram com os filhos, e é uma situação assim que me chamou atenção (H8).

Não (não mudou muito quando elas saíram de casa [ . . . ]). Não tivemos, assim, o ninho vazio, não tivemos (M10).

Elas têm a vida delas e tudo, mas a gente é muito, muito unido. [. . .] Ela vem todo o dia aqui, ela liga para mim, conversa comigo, mas primeira coisa o pai (M10).

Alguns entrevistados destacaram nuances da parentalidade em etapas diferentes do ciclo de vida: casais com filhos pequenos, ninho vazio. M9, que atualmente tem três filhos pequenos, faz distinção da vida de casado sem filhos e com filhos, 
destacando que são momentos completamente diferentes. H8, que tem uma filha adolescente e dois filhos pequenos, enfatiza que as maiores emoções do casamento foram relacionadas aos filhos. M4 acrescenta que, quando os filhos são pequenos, há algum controle da situação, mas, na adolescência, tudo muda. M10 está na fase do ninho vazio e explica que o casal não teve dificuldade para enfrentar esse período do ciclo de vida. Fala que o casal e as filhas são muito unidos e, mesmo depois que as filhas casaram, isso permaneceu. As filhas estão sempre na casa deles, entram em contato todos os dias e são muito apegadas a eles, principalmente ao pai.

\subsubsection{Momentos imprevisiveis}

Representam as influências não normativas, aquelas que não constam no curso de vida esperado, não afetando todos os indivíduos. Por conta da imprevisibilidade, esse período pode gerar grande sobrecarga de estresse para os cônjuges (Baltes, 1987; 1997).

Senti muita solidão, porque eu vim logo morar aqui, sem família nenhuma, sem nenhum apoio familiar, só tinha ele. Então, ou eu me acertava com ele ou ficava sozinha, né? Com filhos e sozinha. Então, senti solidão. Às vezes, senti vontade de voltar para casa, não para morar, eu sempre soube que queria ficar casada, isso eu não tinha dúvida (M2).

O pessoal daqui pra fazer amizade... Já é difícil hoje; naquela época, era pior! E quando chegou o frio, eu disse "Meu Deus, eu quero ir embora! Isso aqui é terra de pinguim". [. . .] Aí, a mão fica toda vermelha por causa do frio, vai ressecando. Eu disse: "Meu Deus do céu!". Vai passando, você vai esquecendo, você vai se habituando (M6).

Eu acho que foi quando eu fui para Guarapuava. Foi um momento bastante triste, porque, quando eu passei, achei que fosse para Curitiba. [. . . Essa foi uma parte bem difícil que aconteceu depois de casado, eu ir para lá e se separar, porque ele ficou aqui (M7).

A mudança de cidade foi relatada por alguns casais como uma representação de momentos imprevisíveis. Quando questionados na entrevista como lidaram com esses momentos, que emoções vivenciaram e que influências tiveram, relataram sentimentos negativos, solidão, impotência, raiva, tristeza, característicos da sobrecarga emocional que podem se apresentar nos momentos imprevisíveis.

Olha, meu Deus! Na verdade, ela foi tomando conta de mim, eu fui rejeitando, você não quer admitir, né? Mas, assim, eu estava totalmente tomada da depressão (M4). 
Eu venho, há muito tempo, tratando uma doença, que é um parasita que éa ameba. [. . .] Aí você começa a ficar um pouco depressivo por causa da doença. [.. .] Você está trabalhando, te dá uma cólica. Isso me deixou muito agressivo (H4).

Olha, recentemente foi que minha mãe teve um câncer, um tumor no nariz. Está até se recuperando, levou ponto, teve um carcinoma abaixo do nariz. Lógico que eu fiquei triste com a notícia. A gente também conversou bastante. Fora isso, não tem motivo nenhum não $(\mathrm{H} 5)$.

É que, em 2006, eu tive um aborto. Eu tive uma gestação embrionária, formou a placenta, mas não formou o embriāo (M9).

As doenças na família, físicas e emocionais, foram apontadas pela maioria dos entrevistados, como eventos não previstos do ciclo de vida do casal, que acarretaram muito estresse e exigiram maior adaptabilidade do par conjugal.

Em agosto, faleceu o pai dele. Aí, eu meio que desencuquei. No dia 25 de janeiro, minha mãe teve derrame. Na verdade, a gente já estava contando que minha mãe fosse cuidar do nosso filho, pra não deixar em creche. Aí, quando minha mãe teve derrame, eu disse não, não é a hora (M9).

Foi o que aconteceu com a gente. Nós trouxemos o nosso filho, e o médico falou que ele não ia viver mais do que dois meses. Na tampa, assim. Então, isso que desestruturou bastante [. . .] porque tira toda a esperança naquele momento. [. . .] Eu fico mais deprimida e tudo, mas ele não. Daí ele fazia eu também superar. Até hoje, eu não superei (M10).

A morte na família também foi mencionada como um dos momentos mais difíceis da vida conjugal. M10 explica que, quase 30 anos depois, não superou a morte do filho e se emociona.

\subsubsection{Momentos previsiveis}

Relacionam-se às influências normativas, eventos que tendem a ocorrer na mesma época e com a mesma duração, para a maioria dos indivíduos (Baltes, 1987; 1997).

"A gente, no início, brigava muito, né? Depois a questão do tempo; com o tempo aí foi diminuindo, foi se encaixando. Um foi se moldando ao outro, foi questão [. . . ] Eu não lembro exatamente quanto tempo" (H5).

O casal 5 retrata o período da formação do casal, enfatizando que, dentro da previsibilidade, tiveram muitas brigas no período de adaptação, mas que foi temporário e, aos poucos, foram se moldando um ao outro. 
Adorei ficar com minhas filhas. Adorei ficar com elas, acompanhar a infância delas. Eu nem pensava em trabalhar nessa época. [...] Mesmo com filhos, a gente viveu momentos muito legais, viagens; nós viajamos muito. E os filhos juntos. Teve seu lado positivo, né? Foi bem legal, né? Ter conseguido se adaptar, recém-casados e com filhos (M2).

Ah, o D. foi muito esperado. Quando a gente descobriu a gravidez, foi uma festa. O período da gravidez foi maravilhoso. Foram meses muito felizes. E, quando ele nasceu, foi um marco, um fechamento de um ciclo, né? E o início de outro. Foi muito bom! (M5)

Não tem tempo pra dormir, você não tem tempo para fazer suas coisas básicas, que dirá cuidar, olhar (M5).

Os relatos acima representam a fase de nascimento dos filhos, na qual os casais precisam aprender a manejar a conjugalidade e a parentalidade, sendo comum acarretar estresse, pela diminuição do tempo em casal e maior dedicação ao filho, à filha. No entanto, os casais 2 e 5 demonstraram capacidade adaptativa para lidar com esse momento específico da conjugalidade.

\subsection{DISCUSSÃO}

Segundo Baltes $(1987$; 1997), o ciclo vital é caracterizado por mudanças previsíveis e imprevisíveis. Definimos momentos previsíveis e imprevisíveis como categorias, considerando que ambos foram mencionados pela maior parte dos entrevistados. Os momentos previsíveis abordados estão relacionados aos primeiros anos de casamento e ao processo de adaptação, ao nascimento dos filhos e ao desafio de manejar a conjugalidade e a parentalidade. É esperado, nos primeiros anos de casamento, uma capacidade de adaptação maior, derivada dos contrastes entre o que se espera da relação e como se apresenta na realidade, as diferenças entre os parceiros e a construção da conjugalidade (Lima \& Alves, 2010). O nascimento de um novo membro da família prevê um processo de estruturação da parentalidade, menos tempo para o casal e uma dedicação maior à criança (Hernandez \& Hutz, 2009). Enfatizamos que, apesar da previsibilidade desses momentos, alguns casais sublinham como períodos muito conturbados para eles, e outros demonstram uma relevante capacidade adaptativa, não tendo graves problemas.

A categoria "formação do novo casal" foi identificada em todas as entrevistas. Participantes que têm menos de dois anos de casados afirmam que o começo foi bem difícil. Entre as dificuldades apontadas, podemos citar as diferenças de gênero, de personalidade e de padrão da família de origem, o que gerou muita discussão e problemas para os cônjuges. Além disso, os contrastes entre o que 
se espera da relação e o como se apresenta na realidade podem desencadear as primeiras frustrações e dificuldades dos cônjuges (Lima \& Alves, 2010).

Como momentos imprevisíveis abordados, destacamos a mudança de cidade, as doenças e a morte precoce na família. Os entrevistados confirmam que essas situações acarretam estresse e exigem uma maior adaptabilidade do par conjugal. McEwen e Lasley (2003) apontam a particularidade desses momentos: a duração do estresse pode ser maior, pelo seu caráter imprevisível. Como exemplo, na fala dos entrevistados, a morte do filho do casal 10 é relatada por M10 com choro e dizendo que, após 30 anos, sofre ao lembrar-se daquele momento. Desse modo, observar os processos críticos que acarretam transformações pessoais e do sistema conjugal possibilita perceber que há uma alteração espontânea nos casais e nas famílias, adequando-se a cada momento específico que estão vivendo (Menezes \& Lopes, 2007). Por isso é importante atentar para história de vida dos casais e os momentos imprevisíveis que passaram. Isso nos aponta para dados importantes do estresse enfrentado e da vida conjugal, pois todo casal enfrenta dificuldades, momentos inesperados na vida, que trazem uma sobrecarga de estresse que influenciam diretamente na relação conjugal.

Delimitamos ainda as categorias "conjugalidade" e "casal e parentalidade", considerando que estas são referidas pela maioria dos casais entrevistados. Em relação à "conjugalidade", as diferenças individuais e a construção da identidade conjugal são descritas como os principais motivos de estresse. As diferenças individuais, tais como um cônjuge ser organizado e o outro desorganizado, a forma como cada um pega na pasta de dente, os hábitos e as manias particulares, a maneira de lidar com os investimentos e gastos são apontados como fontes de estresse, principalmente no começo do casamento. Os relatos apresentados são consistentes, com a compreensão da conjugalidade como um processo de construção de uma realidade comum, na qual cada parceiro experimenta uma reconstrução de sua realidade individual, criando referências comuns e uma identidade conjugal (Féres-Carneiro, 1998). Alguns participantes sublinham que achar o "jeito do casal” é um processo, mas que é importante respeitar o espaço e a individualidade de cada um e ter bastante diálogo na construção da conjugalidade. $\mathrm{O}$ casal 2, que tem 25 anos de casados, refere que, atualmente, não há estresse. Ambos respeitam a individualidade e as diferenças do outro, cada um tem liberdade para fazer a atividade que gosta e respeita o espaço do outro. M2 explica com satisfação que isso contribui para o bem-estar do casal e do tempo em que estão fazendo atividades em conjunto.

A categoria "casal e parentalidade" associa o relacionamento conjugal ao funcionamento dos cônjuges como pais. Os casais demarcam, em seus relatos, questôes relevantes da parentalidade, como a falta de tempo para o casal com o 
nascimento do filho, as dificuldades de coadunar a vida profissional e o cuidado com os filhos e a educação, entre outros. Os casais enfatizam o período de transição para a parentalidade como um momento de estresse para os cônjuges, considerando as mudanças e as adaptaçóes significativas no casamento, visto que são confrontados com os novos desafios de cuidar de uma criança (Whiteman et al., 2007). O casal 5, que tem um filho de 5 meses, enfatiza que o estresse dessa fase é relacionado à falta de tempo para dormir, para fazer suas coisas básicas, inclusive tempo para investir no casal, pois o "relacionamento deixa de ser o foco, para ter o foco no filho" (M5). O nascimento de um filho é um período de estresse para os cônjuges, pois traz exigências que não existiam anteriormente. Ambos precisam se adaptar e se articular para dar conta das novas demandas da parentalidade.

Outras fases do ciclo de vida também foram demarcadas na categoria "casal e parentalidade", como casais com filhos pequenos, casais com filhos adolescentes, ninho vazio. Alguns exemplos se destacam: M4 aponta que há uma mudança em relação ao controle da situação quando os filhos são pequenos e entram na adolescência, mas que não teve mudanças para a conjugalidade; M10 explica que a fase do "ninho vazio" não trouxe dificuldades para o casal, e que a união entre o casal e as filhas permaneceu mesmo depois que as filhas casaram. Não são apontadas diferenças no que se refere ao casal e parentalidade, ou seja, a experiência da parentalidade não afetou a relação do casal. Percebemos que, como pais, esses casais têm cumplicidade e harmonia, de forma a manter a qualidade conjugal, indicando que a relação conjugal é um apoio importante para a parentalidade, pois, quando os pais relatam mais intimidade e comunicação em seu casamento, eles são mais carinhosos com seus filhos (Grych, 2002). Por isso ressaltamos que há uma interferência direta na maneira como o casal constrói a conjugalidade e a parentalidade.

Os casais que estavam ou mencionaram o período de "formação do novo casal" sublinham que foi um momento conturbado, considerando as diferenças individuais e os ajustes que dois indivíduos de famílias de origem diferentes precisam enfrentar (Carter \& McGoldrick, 2001). Por conta destas nuances, o estresse tende a se elevar, se o casal não lançar mão de recursos adequados

A fase do nascimento dos filhos também foi mencionada. $\mathrm{O}$ casal 10 relata o nascimento do filho com má-formação. Esse momento traz uma especificidade que é um evento imprevisível específico, a morte de um filho, que não podemos caracterizar como característico da fase. No entanto pensamos ser importante destacá-lo, tendo em vista representar um acontecimento que gerou estresse e podia ter sido administrado de outra forma. Desse modo, talvez esse evento não fosse ainda tão dolorido para a esposa. Pires (2011) explica que o apoio do 
cônjuge possibilita uma forma de proteção ao estresse diário e, certamente, pode influenciar o nível da resiliência individual e conjugal. Logo, quando há um suporte adequado do cônjuge no momento de estresse, melhores possibilidades de enfrentamento dos desafios são criadas, podendo gerar amadurecimento com essas experiências.

Alguns entrevistados enfatizam que a fase de filhos pequenos não é fácil, devido à administração das atividades da casa, filhos e trabalho, mas que conseguiram manejar essas atividades e que viveram momentos muito "legais", mesmo com filhos pequenos. Vimos, na discussão teórica, que é natural os pais apresentarem dificuldades em cuidar e desenvolver laços afetivos com as crianças, sendo mais natural essa habilidade para a mãe. É comum que a responsabilidade do cuidado com os filhos recaia sobre a mãe, podendo ocasionar estresse para o casal (Carter \& McGoldrick, 2001). Na fase da adolescência, são comuns as discordâncias entre os cônjuges, referente às questôes de autonomia, namoro e sexualidade dos adolescentes, o que pode aumentar o conflito entre o casal (Mussumeci \& Ponciano, 2016). No entanto essas características não foram evidenciadas nas entrevistas.

O casal 8, apesar de ter uma filha adolescente, não abordou o tema, focando em outras questôes do casal e da parentalidade. O casal 4 aborda explicitamente as questôes das dificuldades do período da adolescência, enfatizando que a mãe sofreu muito mais com esses problemas do que o pai. As mães podem ser mais afetadas negativamente pela puberdade de seus filhos, devido à maior convivência, e também devido aos papéis parentais adquirirem significados diferentes (Whiteman et al., 2007). A esposa explica que desenvolveu um processo de depressão quando percebeu que não tinha o domínio sobre os filhos adolescentes e o que projetou para eles não estava acontecendo (em vez de estudar, os filhos só queriam ficar jogando no computador). Acrescenta que é difícil perceber que o exemplo, como pais, e a educação não são determinantes nas escolhas dos filhos adolescentes. Já o marido relata que lidou de uma forma mais tranquila com as dificuldades da adolescência dos filhos, pois tem alunos dessa faixa etária e, por isso, já está acostumado com esses tipos de questôes.

Os casais com mais tempo de casados abordam automaticamente os períodos anteriores do ciclo de vida, relatando como lidaram com as diferentes fases do ciclo de vida conjugal e, ainda, as habilidades utilizadas para administrar os estresses durante todo o processo. Com base nessa característica, concluímos que não houve diferenças que se destacassem em relação às experiências de estresse nos diferentes períodos do ciclo de vida, embora o momento inicial seja considerado o mais estressante, sendo a base para as formas de enfrentamento posteriores, vividas ao longo da trajetória conjugal. 


\section{CONSIDERAÇÕES FINAIS}

A conjugalidade não é estática, mas se constrói ao longo da vida em um processo contínuo, ou seja, a manutenção de habilidades construtivas de enfrentamento de estresse permite a adaptação dos casais aos diversos eventos, às mudanças previsíveis e imprevisíveis. A partir do estudo realizado, constatamos que o estresse e os momentos do ciclo de vida conjugal podem ser experimentados com maior ou menor sofrimento, dependendo das estratégias estabelecidas pelos casais. Com os resultados obtidos nesta pesquisa exploratória, compreendemos a importância de considerar a maneira como os cônjuges administram as situações de estresse. Entendemos, porém, que há uma limitação em basear a pesquisa nos relatos das etapas anteriormente vividas e, por isso, consideramos importante realizar estudos longitudinais, para observar e compreender as diferentes etapas do ciclo de vida conjugal.

Esta pesquisa incita uma reflexão a respeito da importância de se pensar a prática clínica com casais, identificando a forma como enfrentam o estresse e quais são as repercussões para a conjugalidade. Além disso, temos a proposta de criar e estimular o desenvolvimento de programas de intervenção, que se propõem a um trabalho terapêutico com os casais e que possibilitam a construção de ferramentas para lidarem com as experiências de estresse, ratificando a importância do estudo da conjugalidade e das etapas do ciclo de vida conjugal para o enfrentamento positivo das situaçóes estressantes. Acreditamos que as propostas dos programas de intervenção são essenciais, visto que abordam educação, habilidades e princípios que ajudam os indivíduos e os casais a aumentarem a chance de terem êxito no casamento. 


\section{REFERÊNCIAS}

Baltes, P. B. (1987). Theoretical propositions of life-span Developmental Psychology: on the dynamics between growth and decline. Developmental Psychology, 2(5), 611-626.

Baltes, P. B. (1997). On the incomplete architecture of human ontogeny: selection, optimization, and compensation as a foundation of developmental theory. American Psychologist, 52, 366-380.

Bardin, L. (2008). Análise de conteúdo. Lisboa: Edição Setenta.

Baumeister, R. F., \& Leary, M. R. (1995). The need to belong: desire for interpessoal attachments as a fundamental human motivation. Psychological Bulletin, 117(3), 497-529.

Bodenmann, G. (2005). Dyadic coping and its significance for marital functioning. In T. Revenson, K. Kayser, \& G. Bodenmann (Eds.), Couples coping with stress: emerging perspectives on dyadic coping. (pp. 33-50). Washington: American Psychological Association.

Bodenmann, G., Meuwly, N., \& Kayser, K. (2011). Two conceptualizations of dyadic coping and their potential for predicting relationship quality and individual well-being. European Psychologist, 16(4), 255-266.

Bolze, S., Schmidt, B., Crepaldi, M., \& Vieira, M. (2013). Relacionamento conjugal e táticas de resolução de conflito entre casais. Actualidades em Psicologia, 27(114), 71-85.

Carter, B., \& McGoldrick, M. (2001). As mudanças no ciclo de vida familiar: uma estrutura para a terapia familiar. (2a ed.) Porto Alegre: Artes Médicas.

Faro, A., \& Pereira, M. E. (2013). Estresse: revisão narrativa da evolução conceitual, perspectivas teóricas e metodológicas. Psicologia, Saúde \& Doenças, 14(1), 78-100.

Féres-Carneiro, T. (1998). Casamento contemporâneo, o difícil convívio da individualidade com a conjugalidade. Psicologia: Reflexão e Crítica, 11(2), 379394.

Féres-Carneiro, T. (2003). Construção e dissolução do laço conjugal na psicoterapia de casal. In T. Féres-Carneiro (Org.), Familia e casal: arranjos e 
demandas contemporâneas. (pp. 201-214). Rio de Janeiro: PUC Rio, São Paulo: Loyola.

Folkman, S., \& Lazarus, R. S. (1980). An analysis of coping in a middle-aged community sample. Journal of Health and Social Behavior, 21, 219-239.

Fontanella, B. J. B., Rica, J., \& Turato, E. R. (2008). Amostragem por saturação em pesquisas qualitativas em saúde: contribuições teóricas. Cadernos de Saúde Pública, 24(1), 17-27.

Grych, J. H. (2002). Marital relationships and parenting. In M. Bornstein, Handbook of parenting (Vol. 4). London: LEA Mahwah.

Hernandez, J. A. E., \& Hutz, C. S. (2009). Transição para a parentalidade: ajustamento conjugal e emocional. Psico, 4, 414-421.

Lakey, B., \& Orehek, E. (2011). Relational regulation theory: a new approach to explain the link between perceived social support and mental health. Psychological Review, 118(3), 482-495.

Lazarus, R. (1993). From psychological stress to emotions: a history of changes outlooks. Annual Reviews of Psychology, 44, 1-21.

Lazarus, R., \& Folkman, S. (1984). Stress, appraisal, and coping. New York: Springer.

Lima, R. A., \& Alves, I. C. A. (2010). As particularidades da (in) satisfação conjugal antes e depois da chegada dos filhos. Boletim Academia Paulista de Psicologia, 30(79), 424-439.

Menezes, C., \& Lopes, R. C. S. (2007). Relação conjugal na transição para a parentalidade: gestação até dezoito meses do bebê. Psico-USP, 12(1) 83-93.

McEwen, B., \& Lasley E. N. (2003). O fim do estresse como nós o conhecemos. Rio de Janeiro: Nova Fronteira.

Moal, M. L. (2007). Historical approach and evolution of the stress concept: a personal account. Psychoneuroendocrinology, 32, 3-9.

Mussumeci, A. A. (2016). Coping diádico ao longo do ciclo de vida conjugal. (Dissertação de Mestrado). Universidade Estadual do Rio de Janeiro, Programa de Pós-Graduação em Psicologia, Rio de Janeiro. 
Mussumeci, A. A., \& Ponciano, E. L. T. (2016). Conjugalidade e relacionamento pais e filhos: pesquisas e propostas de intervenção. In E. L. T. Ponciano, \& M. L. Seidl-de-Moura (Orgs.), Quem quer crescer: relacionamento pais e filhos(as) da adolescência para a vida adulta. (pp. 153-178). Curitiba: CRV.

Oatley, K., \& Jenkins, J. M. (2002). Compreender as emoçôes. Porto Alegre: Instituto Jean Piaget.

Pires, A. R. A. (2011). Coping diádico e satisfação conjugal: um estudo em casais portugueses (Dissertação de Mestrado). Universidade de Lisboa, Faculdade de Psicologia, Lisboa.

Ponciano, E. L. T. (2015). Autoridade parental em transformação: pais e filhos na adultez emergente. In T. Féres-Carneiro (Org.), Família e casal: parentalidade e filiação em diferentes contextos. (pp. 57-72). Rio de Janeiro: PUC Rio, São Paulo: Perspectiva.

Ponciano, E. L. T., \& Féres-Carneiro, T. (2014). Relação pais-filhos na transição para a vida adulta, autonomia e relativização da hierarquia. Psicologia: Reflexão e Critica, 27(2), 388-397.

Ponciano, E. L. T., \& Seidl-de-Moura, M. L. (2011). Identity and parentschildren's relationship in the transition to adulthood. In G. Moita, A. R. Torres, $\&$ L. Ribeiro (Eds.), Proceedings of $4^{\text {th }}$ Regional Mediterranean and Atlantic Congress of the IAGP. (pp. 115-124). Porto: IAGP.

Rook, K. S., Luong, G., Sorkin, D. H., Newsom, I. J. T., \& Krause, N. (2012). Ambivalent versus problematic social ties: implications for psychological health, functional health, and interpersonal coping. Psychology and Aging, 27(4), 912-923.

Simonton, C., Matthews-Simonton, S., \& Creighton, J. L. (1987). Com a vida de novo: uma abordagem de autoajuda para pacientes com câncer. (6a ed.). São Paulo: Summus.

Story, L. B., \& Bradbury, T. N. (2004). Understanding marriage and stress: essential questions and challenges. Clinical Psychology Review, 23, 1139-1162.

Vásquez, N. S. M., Posada, J. J. Z., \& Messager, T. (2015). Conceptualización de ciclo vital familiar: una Mirada a la producción durante el period comprendido entre los años 2002 a 2015. Revista CES Psicología, 8(2), 103-121. 
Whiteman S. D., McHale, S. M., \& Crouter, A. C. (2007). Longitudinal changes in marital relationships: the role of offspring's pubertal development. Journal of Marriage and Family, 69, 1005-1020. 